\title{
Analysis of Ocular Axial Length and Anterior Chamber Depth in Port Harcourt, Nigeria
}

\author{
IN Aprioku ${ }^{1}$ and CS Ejimadu ${ }^{2 *}$ \\ ${ }^{1}$ Department of ophthalmology, Rivers State University, Nigeria \\ ${ }^{2}$ Department of Ophthalmology, University of Port Harcourt, Nigeria
}

*Corresponding author: Chibuike Sydney Ejimadu, Department of Ophthalmology,

Received Date: July 16, 2019

University of Port Harcourt, Nigeria.

Published Date: August 06, 2019

\begin{abstract}
Aim: To determine the relationship between Ocular axial length (AL) and anterior chamber depth (ACD) in a normal population in Port Harcourt City Local Government Area (LGA).

Method: This was a multistage random sampling community based descriptive study carried out in Port Harcourt City LGA. The inclusion criteria were Visual Acuity $>6 / 18$, age greater than 18 years with no history of past ocular surgeries or trauma. Data obtained through an interviewer administered structured proforma included age, sex, tribe, occupation and level of education. Ocular examinations done included visual acuity, applanation tonometry, and ophthalmoscopy. Axial length (AL) and Anterior Chamber Depth (ACD) were measured using Amplitude (A) scan ultrasonography (SONOMED PACSCAN 300AP). Data were analyzed using SPSS (Version 17), and p value was set at $\leq 0.05$.

Results: Four hundred and sixty-six (466) subjects participated in the study made up of two hundred and twelve (212) males (45.5\%) and two hundred and fifty-four (254) females (54.5\%) with M: F ratio of 1:1.2. The age range was 18-92 years and mean age of the subjects studied $43.0 \pm 14.2$ years. Findings revealed mean AL and ACD to be $23.2 \pm 1.0 \mathrm{~mm}$ and $3.1 \pm 0.5 \mathrm{~mm}$ respectively. The mean AL and ACD were greater in males than females. There was no statistically significant relationship between age and axial length but there was a statistically significant relationship between age and ACD. Males had longer AL than females which was statistically significant. It was also noted that for every millimeter increase in AL, there was a $0.07 \mathrm{~mm}$ rise in ACD in the general population. $(r=0.253, p=0.000)$.
\end{abstract}

Conclusion: This study noted that for every millimeter increase in AL, there was a $0.07 \mathrm{~mm}$ rise in ACD in the general population. ( $\mathrm{r}=0.253$, $\mathrm{p}=0.000$ ) and the values are higher in males. This relationship may be used to derive simple mathematical formulae for use in keratometer and also add to the data bank for AL and ACD.

Keywords: Ocular; Axial; Length; Anterior; Chamber; Depth; Port; Harcourt

\section{Introduction}

Axial Length (AL) and Anterior Chamber Depth (ACD) measurement is important in determination of the refractive status of the eye as well as determination of intraocular lens power for patients prior to cataract surgery. The relationship between axial length and anterior chamber has been studied over time. They have been related to some ocular parameters [1]. The axial length is the most important anthropometric variable in the calculation of Intra ocular Lens power as a $0.1 \mathrm{~mm}$ error in its measurement will result in as much as $0.25 \mathrm{D}$ change in post-operative refraction. Axial length is a quantifiable variable measured either by ultrasonography (which could be by contact or immersion techniques; amplitude (A) Scan or brightness (B) Scan) or by optical methods (Partial Coherence Interferometry) [2].
Axial length is defined as the distance between the anterior and the posterior poles of the eye or as the distance from the anterior curvature of the cornea to the retinal pigment epithelium in alignment along the optical axis of the eye [2,3]. At birth, the axial length is approximately $17-18 \mathrm{~mm}$; following which it increases by about $5 \mathrm{~mm}$ (up to $23 \mathrm{~mm}$ ) from birth to age 3-6years until it reaches an average of $24 \mathrm{~mm}$ in adulthood [3]. Mean axial length in the Blue mountain eye study, [4] was $23.44 \mathrm{~mm}$, values noted for the Tanjong Pagar study, [5] in China was $23.23 \mathrm{~mm}$, while that gotten by Adio et al. [6] in Nigeria was $23.57 \mathrm{~mm} \pm 1.19$ which is in agreement with previously documented literature. It has been found from previous studies, to be affected by age and sex [7-9] and anterior chamber depth [10-13]. Previous studies have also 
shown a relationship between short axial length of the eye and an increased incidence of retinal vein occlusions [14], primary angle closure glaucoma,10 and hypermetropia while longer axial lengths have been noted to be associated with an increased incidence of cataracts [15], and myopia. Axial length is also said to have an influence on emmetropisation of the eye [16]. It is also the most important parameter in the calculation of intraocular lens power prior to cataract surgery and helps in the diagnosis of pathological conditions like staphyloma and risk of retinal detachment [7]. Therefore there is a need to know the normal values of the axial length in our environment which can subsequently be used as a yardstick to detect those with abnormal values, and subsequently screen them for the associated pathological conditions.

The anterior chamber depth (ACD), defined as the distance measured along the eye's optical axis from the posterior surface of the cornea to the anterior surface of the crystalline lens [17], is an important biometric measurement. It is approximately $3.5 \mathrm{~mm}$ (1.99-4.75mm). In a study carried out in Central India by Jonas et al. [18], mean anterior chamber depth was noted to be $3.2 \mathrm{~mm}$. Anterior chamber depth varies with age and sex [19]. ACD measurement and dimensions are said to be very important in the diagnosis of angle closure glaucoma, as shallow anterior chamber depth is noted to be one of the most consistent and important ocular risk factors for angle closure glaucoma $[9,15,19]$ in Spain, Europe, reported a linear relationship between anterior chamber depth and axial length up to $27 \mathrm{~mm}$ after which there was a decline and the linear relationship ceased to exist. Jivraka et al. [20], in California USA also showed a positive correlation between axial length and anterior chamber depth. In the same vein, the Beijing eye study [21], carried out in Asia reported significant association between axial length and a deeper anterior chamber In the Beaver dam eye study8, carried out in North America, on 1968 older white persons, AL was found to positively correlate with ACD. Similarly, in another cross-sectional study carried out by Elabjer et al. [22], on 1000 emmetropes, axial length was also found to positively correlate with anterior chamber depth although the correlation was said to be weak.

In another study by Yebra-pimentel et al. [23], anterior chamber depth was found to positively and significantly correlate with axial length in eyes with AL less than $24 \mathrm{~mm}$. This relationship was not seen in those eyes greater than $24 \mathrm{~mm}$. This was similar to findings in Spain, Europe by Jm G and his cohorts [24], where anterior chamber depth was also found to correlate significantly with axial length in eyes less than $24 \mathrm{~mm}$ but not in longer eyes.

A study by Chen et al. [25] on the relationship between central corneal thickness, refractive error, corneal curvature, anterior chamber depth and axial length in 500 normal Taiwanese Chinese adults aged 40-80 years, showed that eyes with axial elongation tended to have deeper anterior chambers, with the correlation being statistically significant although this study did not compare ocular parameters with anthropometric findings.

\section{Results}

Four hundred and sixty-six (466) subjects from the general adult population were studied. The Anterior Chamber Depth (ACD) and Axial Length (AL) values in one randomly selected eye of the population studied were analysed. The mean age of the subjects studied was $43.0 \pm 14.2$ years with the age distribution between 18 and 91 years, and a peak age group of between 31 and 40 years as shown in Figure 1. The mean age for males was $41.6 \pm 12.7$ years and that for females $44.8+15.8$ years (Figure 1).

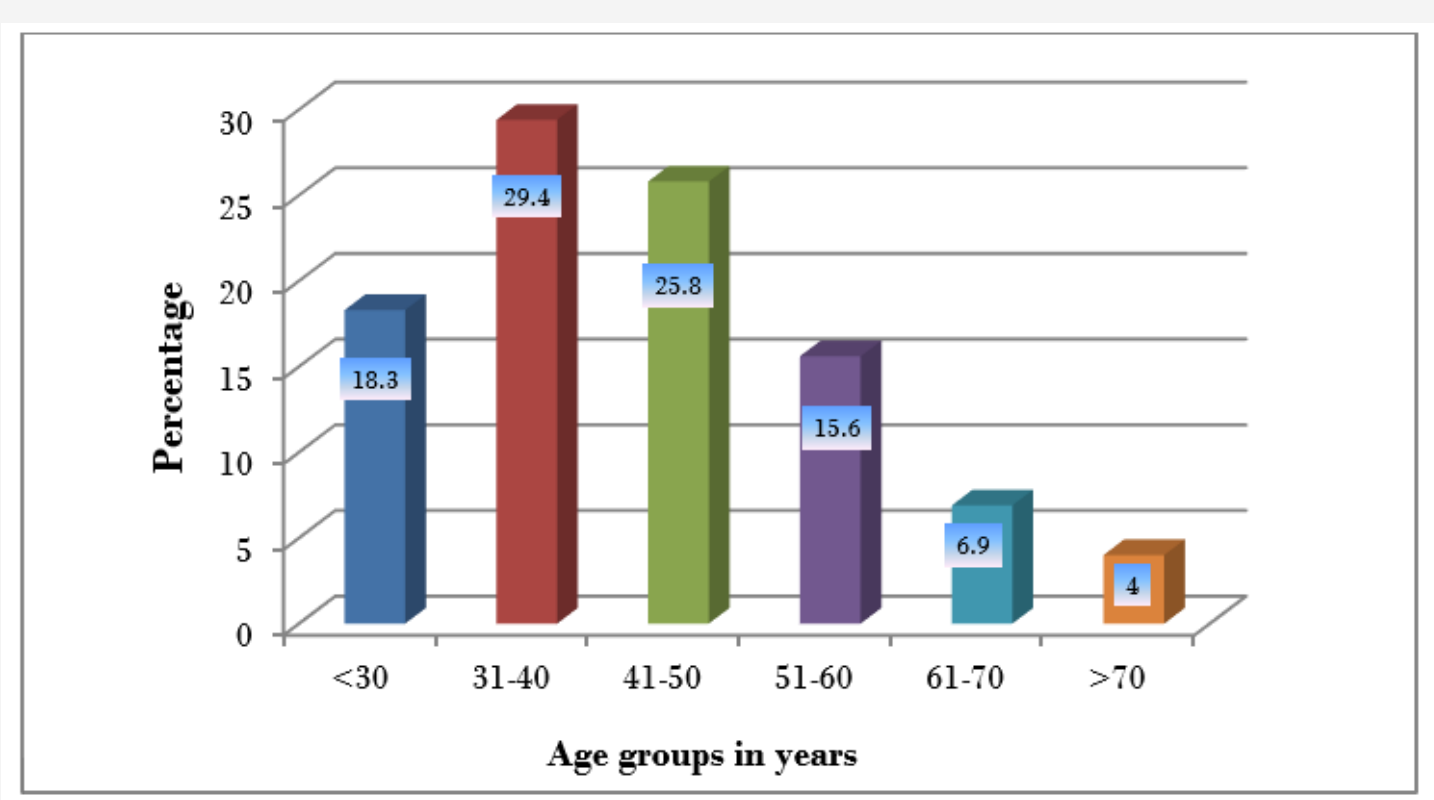

Figure 1: Age distribution of study population.

There were two hundred and twelve (212) males (45.5\%) two hundred and fifty-four (254) females (54.5\%) with male to female ratio of 1:1.2. The gender distribution for different ages is shown in Table 1. About one quarter of the males in the population studied, 
( $\mathrm{n}=54 ; 25.5 \%$ of total male population) were within 41 and 50 years and majority of the female population ( $n=83 ; 32.6 \%$ of female population) were within 31 and 40 years. There was a significant difference between both genders at different age groups $(\mathrm{p}=0.01)$ (Table 1) (Figure 2).

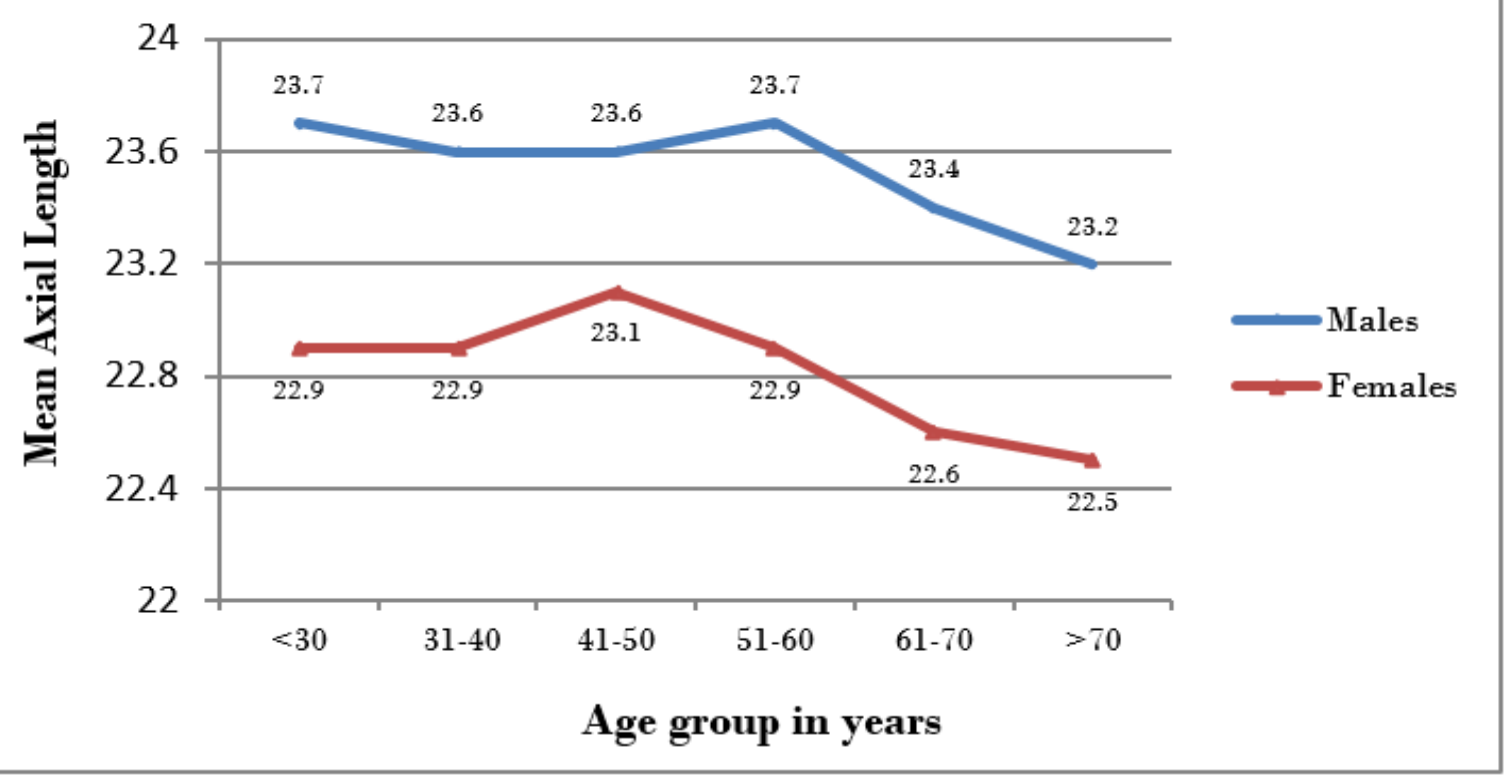

Figure 2: Mean Axial length between genders at different age groups.

Table 1: Gender distribution of different age groups.

\begin{tabular}{|c|c|c|c|}
\hline Age groups / Gender & Male (N\%) & Female (N\%) & Total (N\%) \\
\hline$<30$ years & $43(51.2)$ & $41(48.8)$ & $84(18.0)$ \\
\hline $31-40$ years & $48(36.6)$ & $83(63.4)$ & $131(28.1)$ \\
\hline $41-50$ years & $54(43.5)$ & $70(56.5)$ & $124(26.6)$ \\
\hline $51-60$ years & $38(50.7)$ & $37(49.3)$ & $75(16.1)$ \\
\hline $61-70$ years & $14(42.4)$ & $19(57.6)$ & $33(7.1)$ \\
\hline$>70$ years & $15(78.9)$ & $4(21.1)$ & $19(4.1)$ \\
\hline Total & $212(45.5)$ & $254(54.5)$ & $466(100.0)$ \\
\hline
\end{tabular}

$X^{2}=6.52, d f=1, p$-value 0.01

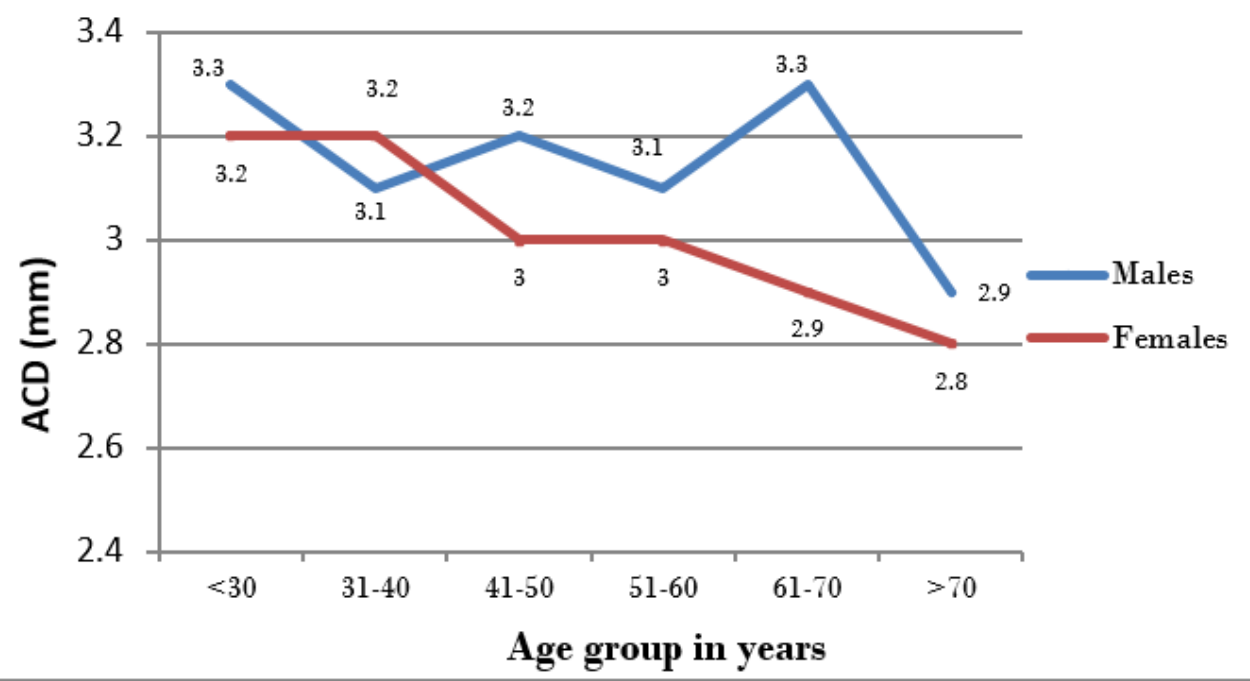

Figure 3: Mean ACD distribution between genders at different age groups. 
The mean ACD of the general adult population studied was $3.1 \pm 0.5 \mathrm{~mm}$ (range 2.5 to $6.5 \mathrm{~mm}$ ). The mean ACD distribution in males was $3.2 \pm 0.3 \mathrm{~mm}$ ( 2.5 to $4.0 \mathrm{~mm}$ ) and in females $3.1 \pm 0.6$ $\mathrm{mm}$ (2.5 to $6.5 \mathrm{~mm}$ ). The mean difference between genders was $0.1 \pm 0.1$ (95\% C.I -0.02 to 0.1 , $\mathrm{t}$-value 1.4 and $\mathrm{p}=0.172$ ). The mean distribution of ACD in different age groups between genders is shown in Figure 3. The peak mean ACD in males was found among those within 61 and 70 years while in females was within 18 and 40 years (Figure 3 ).

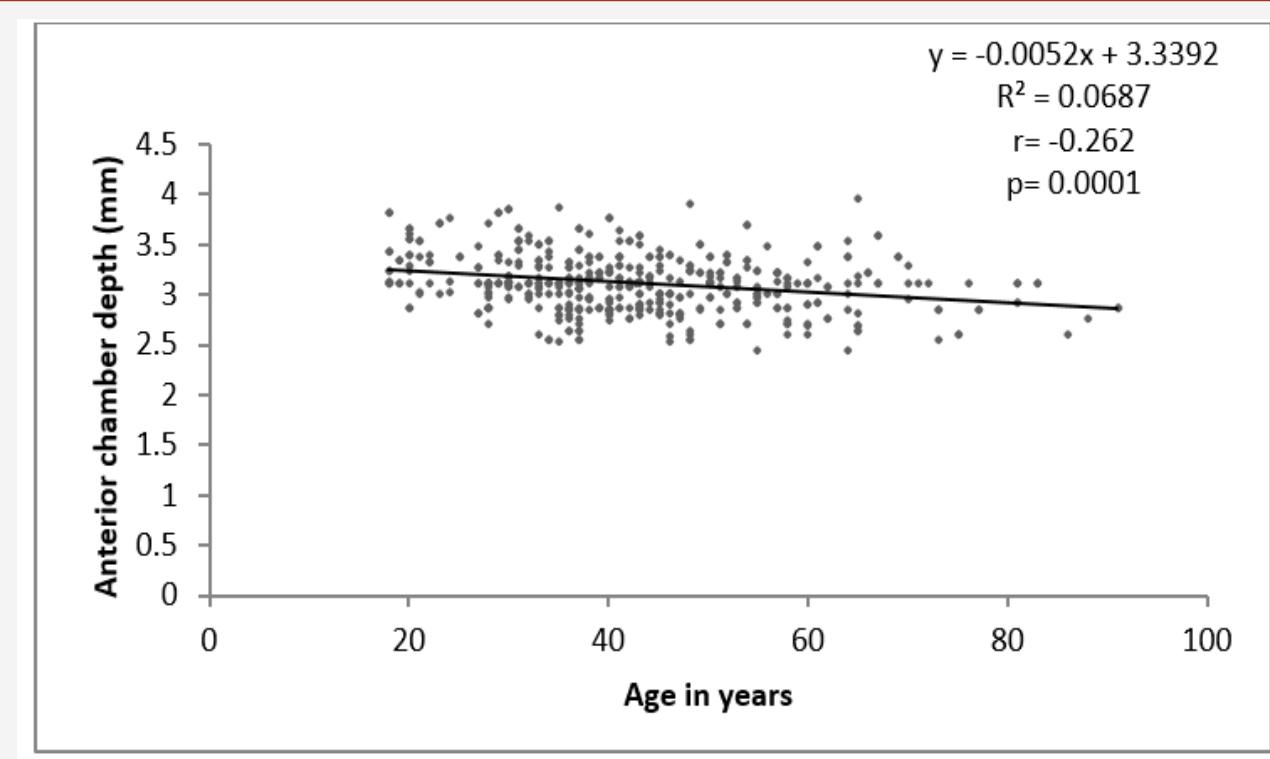

Figure 4: Relationship between Age and ACD in general population.

Bivariate linear regression

Figures 4 shows that a statistically significant negative relationship was found between age and ACD in the general population studied $(r=-0.262, p=0.0001)$ that for every increase in age by 1 year, ACD narrows by $-0.005 \mathrm{~mm}$ (C.I -0.007 to $-0.003 \mathrm{~mm}$ at a constant value of 3.339). This generates the hypothetical equation for ACD estimation from age as ACD $=3.339-0.005$ (age in years) (Figure 4).

The relationship between age and ACD between gender was analysed and it showed that a strong negative relationship existed between age and ACD in both genders respectively $(\mathrm{p}<0.05)$. Among the male population a unit rise in age caused a decrease in ACD by $-0.004 \mathrm{~mm}$ (CI -0.007 to -0.002 ) while in the females a decrease in ACD value by $-0.007 \mathrm{~mm}(\mathrm{CI}-0.01$ to -0.005$)$ was found.

Figure 5 showed that there was a strong positive relationship between AL and ACD in the general population ( $r=0.253$, p-value $=0.000$ ). For everyone millimetre increase in $\mathrm{AL}$, there was a rise in ACD by $0.07 \mathrm{~mm}$ (CI 0.046 to $0.094 \mathrm{~mm}$ at a constant of 1.489 ). This generates a hypothetical equation for ACD from AL as: ACD $=1.489$ +0.07 (AL in $\mathrm{mm}$ ) (Figure 5).

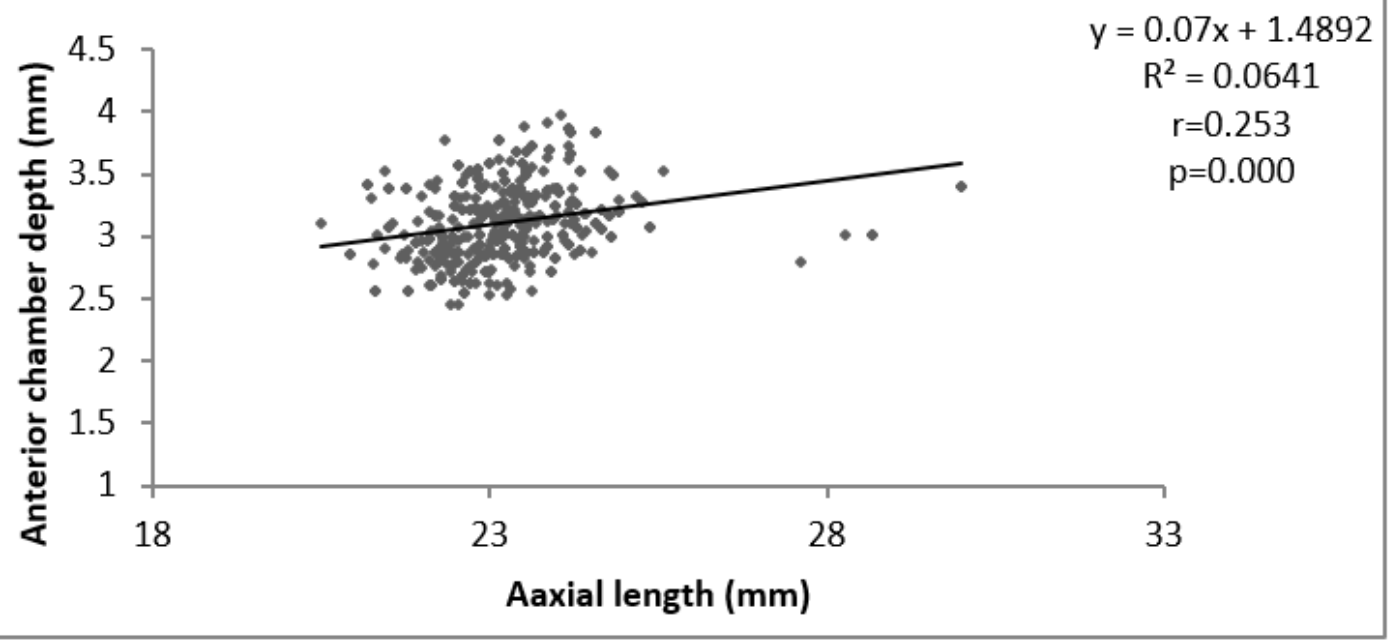

Figure 5: Relationship between $A L$ and $A C D$ in general population. Bivariate linear regression 
Figure 6 showed that in the male population, no significant relationship was found between AL and ACD ( $p=0.168$ ). However among the female population a strong positive relationship was found between AL and ACD ( $r=0.372, p=0.000)$ that for every unit rise in AL, there was an increase in ACD by $0.023 \mathrm{~mm}$ (CI 0.094 to $0.176 \mathrm{~mm}$ ) as shown in (Figure 6,7).

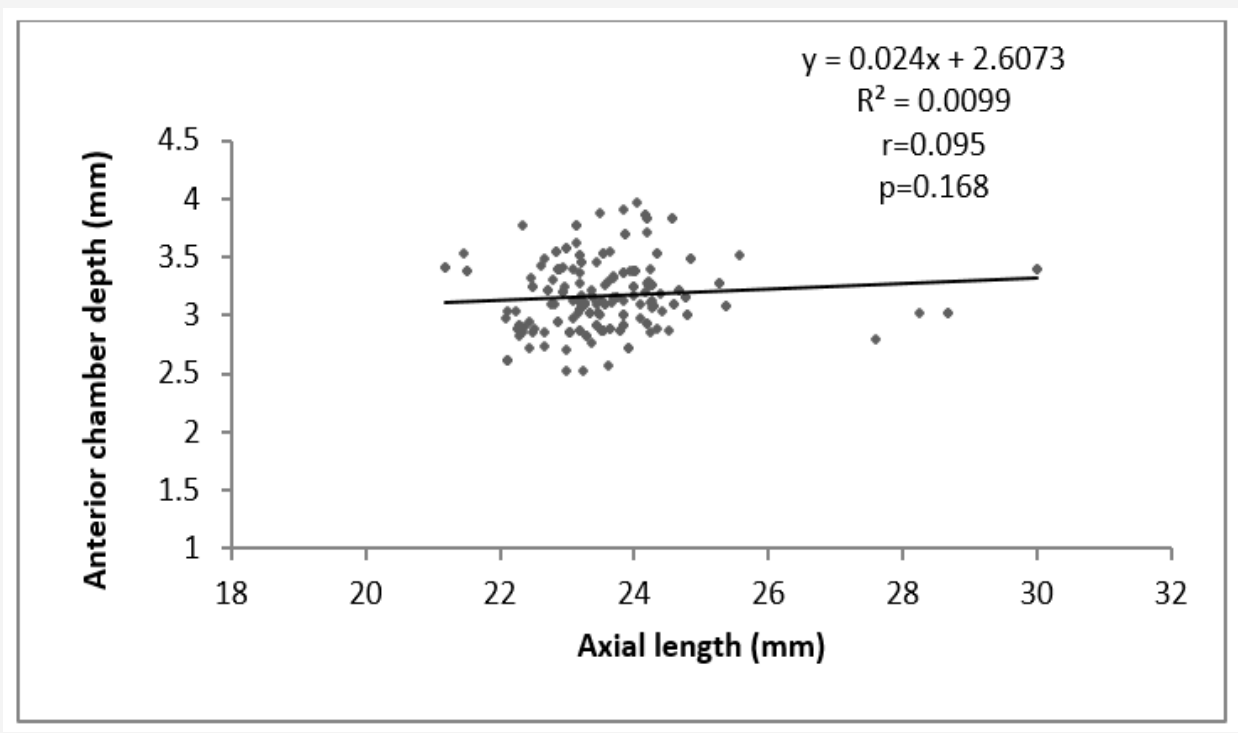

Figure 6: Relationship between AL and ACD in males.

Bivariate linear regression

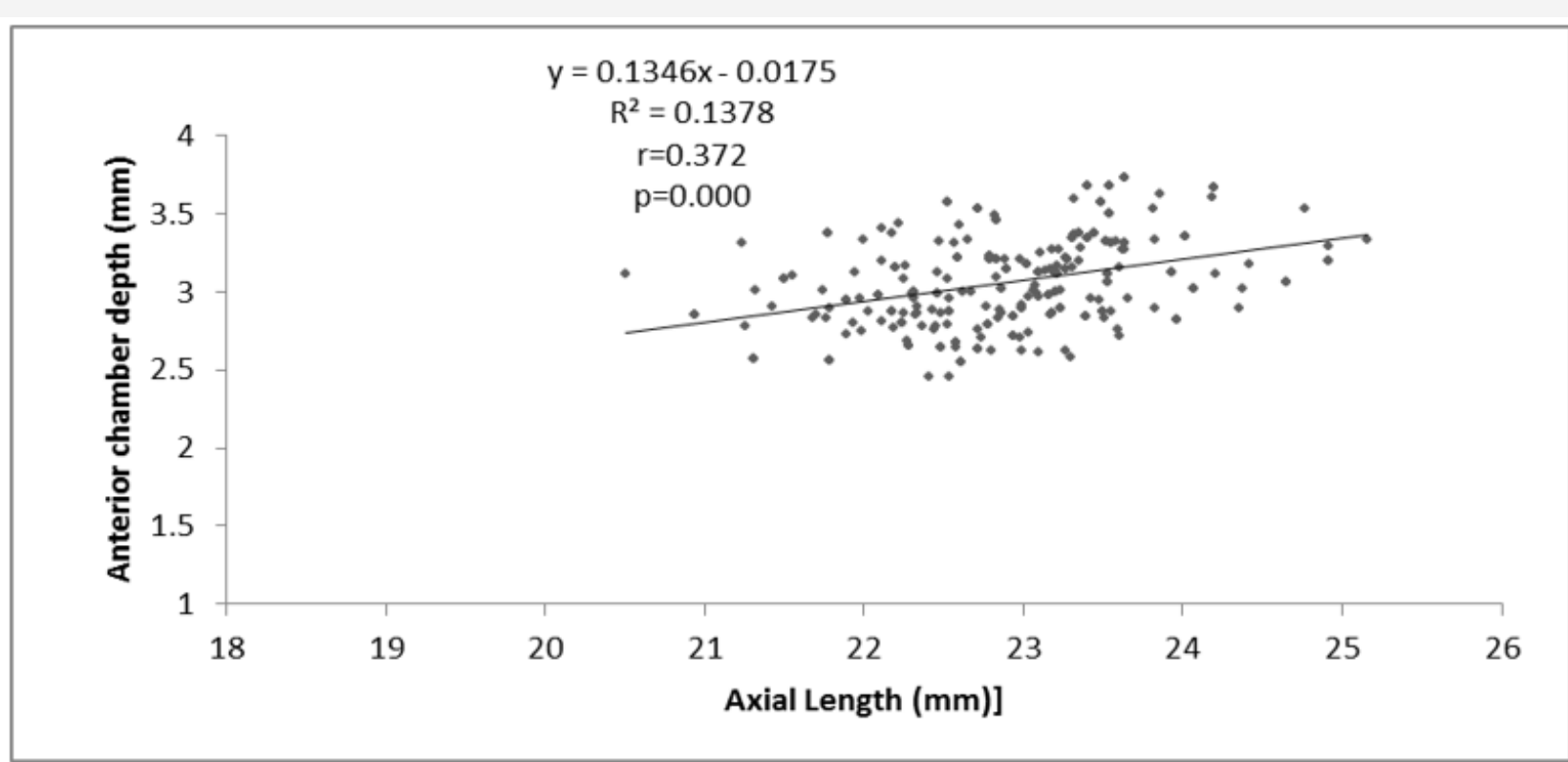

Figure 7: Relationship between AL and ACD in females.

Bivariate linear regression

\section{Discussion}

This study is on axial length and anterior chamber depth in normal adults in the communities of Port Harcourt City Local Government Area of Rivers State, Nigeria, with a view of establishing any relationship between them and other ocular conditions. Most of the subjects studied were of Rivers ethnicity ( $n=184 ; 39.5 \%$ ) which could be explained by the fact that the study was carried out in the communities that make up Port Harcourt city LGA. This was similar to the study carried out by Adio [6] on 400 subjects in UPTH eye clinic where $56 \%$ of the subjects were from Rivers state. Most of the subjects were businessmen and women which may probably be due to the fact that Port Harcourt is largely a commercial city.
The mean axial length of the population in this study was $23.2 \pm 1.0 \mathrm{~mm}$ which was similar to the values noted by Connell et al. [26], (23.03 $\pm 1.61 \mathrm{~mm})$, Hashemi et al. [7] (23.14mm) and the Beijing eye study, [29] (23.25 \pm 1.14$)$. It was however slightly lower than that obtained by Adio et al. $(23.57 \pm 1.19 \mathrm{~mm})$ and Iyamu et al. [13] $(23.5 \pm 0.70 \mathrm{~mm})$. This difference may have been attributed to the fact that the former was a hospital-based study and may not have been representative of the population. While the latter had a smaller sample size $(\mathrm{n}=95)$ and had an age range of 20-69 years as opposed to this study which had an age range of 18-91years. The younger age range may have attributed to the higher mean axial length since it has been noted in several studies that there is 
a decline in axial length with older age. The study by Iyamu et al also had a male to female ratio of $1.4: 1$ as opposed to this study (1:1.2). The higher proportion of males in the study by Iyamu may have further attributed to the higher mean axial length since axial length has been noted to be higher in males than females. The mean axial length in this study was also noted to be lower than that in the Central India eye study $(22.66 \mathrm{~mm})$. This may be related to the lower height and BMI values in the Indian population $(1.56 \pm 0.09 \mathrm{~m}, 19.37 \pm \mathrm{kg} / \mathrm{m} 2)$.

In this study, males were found to have significantly longer axial lengths than females with a mean difference of $0.7 \pm 0.1 \mathrm{~mm}$ $(p=0.0001)$ Figure 2, 3. This was similar to studies carried out by Adio et al. [6] in Nigeria, Hashemi et al. [7]in Iran, Lee et al. [8] in Britain and the Tanjong Pagar eye study [5] and the Central India eye study,1where males were found to have higher axial lengths than females but dissimilar to the Beijing eye study where there was no statistically significant difference between the axial length in males and females and the study on Nigerians by Iyamu et al. [13] where the mean axial length in females was higher than that in males. This difference in pattern may have been due to the fact that the sample size in the study by Iyamu was small $(n=95)$ with a smaller proportion of female. The age range of the sampled females is also not known as this may have affected the relative mean axial length if the females in the population were younger.

The longest axial length in males in this study was seen within age group 51 to 60 years which was similar to that found by Lee et al. [8] who stated that adults younger than 65 years had larger eyes than those aged 75 years and above while in females the longest mean axial lengths were noticed amongst the age group 41 to 50 years similar to that obtained by the Tanjong Pagar eye study.

There was no statistically significant relationship between axial length and age in both gender on bivariate linear analysis in this study (Figure 3,4), this was similar to the results got by Iyamu et al. [13] where regression analysis performed on axial length and age showed no statistical significance $(p=0.46)$, and Connell et al. [26] in Eritrean eyes who stated that there was no correlation between age and biometric readings of his subjects. The mean anterior chamber depth in this study was $3.1 \pm 0.5 \mathrm{~mm}$ Figure 2 which was similar to that noted by Olurin et al. [27] (3.23mm) in Nigerians , the Blue mountain eye study $(3.10 \mathrm{~mm})$ and the Central India Eye study,18 $(3.2 \mathrm{~mm})$ whilst being higher than the values noted in the study on Iranians by Hashemi et al. [7] (2.62 mm). The difference in the mean anterior chamber depths in these populations may not have been unrelated to the smaller sample size in the Cameroonian study (n=325 eyes) and the fact that Iranians have been postulated to have a low ACD [7]. The lower mean ACD values amongst the Iranians may also be related to the fact that the Iranian study was carried out amongst those aged 40 to 70 years, this is in agreement with several studies $[27,28]$ and the index study that notes that ACD reduces with age.

The mean distribution of ACD in males $(3.2 \mathrm{~mm})$ in this study was shown to be higher than that in females $(3.1 \mathrm{~mm})$, although this difference was not statistically significant similar to the study by Elabjer et al. [22] where it was noted that there was no statistically significant difference of right eye ACD between both genders. This result differed from that noted by the EPIC-Norfolk study [9] and the Los Angeles-Latino eye study [29], and Reykjavik eye study where there was a statistically significant higher value of ACD for males as compared to females $(\mathrm{p}<0.001)$.

There was noted to be a strong negative relationship between ACD and age in this study in both gender $(\mathrm{p}<0.05)$, as an increase in age by one year caused a $0.004 \mathrm{~mm}$ and $0.007 \mathrm{~mm}$ decrease in ACD in females and males respectively. This was similar to results got by Hashemi et al. [7] where ACD was noted to decrease by $0.013 \mathrm{~mm}$ per year of aging. This is also in agreement with the EPIC-Norfolk study [9] and the study by Hosny et al. [19] where there was found to be statistically significant inverse relationships between ACD and age.

There was a significant positive relationship between ACD and AL in the study population although this correlation was not statistically significant for the male gender (Figure 5, 6, 7). This finding was similar to that noted in the Epic-Norfolk study [9] which showed a positive correlation between ACD and AL and the Beijing eye study[21] where longer AL were associated with deeper ACD and in the study by Pereira et al. [30] where positive correlations were noted between AL and ACD

\section{Conclusion}

From this study, it shows that there were correlations between ACD and age as well as Axial length and ACD in the study population. On applying a regression model on these associated ocular parameters, it was noted that regarding age, with each one year increase in age, ACD becomes shallower by $0.005 \mathrm{~mm}$ Figure 6 and that in the general population, for every rise in AL by one $\mathrm{mm}$, there is an increase in ACD by $0.07 \mathrm{~mm}$ Figure 5 . Equations formulated from the coefficients obtained in the regression model in keeping with the Pereira study, are thus: Estimated AL in $\mathrm{mm}=16.91+0.039$ (height in $\mathrm{cm}$ ), Estimated ACD $=3.339-0.005$ (Age in years), ACD= 0.007 (Axial length in $\mathrm{mm}$ ) +1.4892 .

\section{Acknowledgement}

None.

\section{Conflicts of Interest}

No conflicts of interest.

\section{References}

1. Nangia V, Jonas JB, Matin A, Kulkarni M, Sinha A, et al. (2010) Body height and ocular dimensions in the adult population in rural Central India, The Central India Eye and Medical Study. Graefes Arch Clin Exp Ophthalmol 248(11): 1657-1666.

2. Axial length (2013) Encycl Ophthalmol.

3. Butterworth-Heinemann (2014) Axial length of the eye. ( $7^{\text {th }}$ Edn.) Dict Optom Vis Sci.

4. Fotedar R, Wang JJ, Burlutsky G, Morgan IG, Rose K, et al. (2010) Distribution of axial length and ocular biometry measured using partial coherence laser interferometry (IOL Master) in an older white population. Ophthalmology 117(3): 417-423. 
5. Wong TY, Foster PJ, Ng TP, Tielsch JM, Johnson GJ, et al. (2001) Variations in ocular biometry in an adult Chinese population in Singapore: The Tanjong Pagar survey. Invest Ophthalmol Vis Sci 42(1): 73-80.

6. Adio AO, Onua AA, Arowolo D (2010) Ocular Axial Length and Keratometry Readings of Normal Eyes in Southern Nigeria. Niger J Ophthalmol 18(1): 12-14.

7. Hashemi H, Khabazkhoob M, Miraftab M, Emamian MH, Shariati M, et al. (2012) The distribution of axial length, anterior chamber depth, lens thickness and vitreous chamber depth in an adult population of Shahroud, Iran. BMC Ophthalmol 12: 50.

8. Lee KE, Klein BEK, Klein R, Quandt Z, Wong TY (2009) Association of age, stature, and education with ocular dimensions in an older white population. Arch Ophthalmol 127: 88-93.

9. Foster PJ, Broadway DC, Hayat S, Luben R, Dalzell N, et al. (2010) Refractive error, axial length and anterior chamber depth of the eye in British adults: the EPIC-Norfolk Eye Study. Br J Ophthalmol 94(7): 827830 .

10. Lavanya R, Wong T-Y, Friedman DS, Aung HT, Alfred T, et al. (2008) Determinants of angle closure in older Singaporeans. Arch Ophthalmol 126(5): 686-691.

11. Sayegh FN (1996) The correlation of corneal refractive power, axial length, and the refractive power of the emmetropizing intraocular lens in cataractous eyes. Ger J ophthalmol 5(6): 328-331.

12. Sherpa D BB (2008) Association between axial length of the eye and primary angle closure glaucoma. Kathmandu Univ Med J 6(23): 361363.

13. Iyamu E, Iyamu JE, Amadasun G (2013) Central corneal thickness and axial length in an adult Nigerian population. J Optom 6(3): 154-160.

14. Cekiç O, Totan Y, Aydin E, Pehlivan E, Hilmioglu F (1999) The role of axial length in central and branch retinal vein occlusion. Ophthalmic Surg Lasers 30(7): 523-527.

15. Hoffer KJ (1993) Axial dimension of the human cataractous lens. Arch Ophthalmol 111(7): 914-918.

16. Pennie FC, Wood IC, Olsen C, White S, Charman WN (2001) A longitudinal study of the biometric and refractive changes in full-term infants during the first year of life. Vision Res 41(21): 2799-2810.

17. Patel RP, Pandit RT (2012) Comparison of Anterior Chamber Depth Measurements from the Galilei Dual Scheimpflug Analyzer with IOLMaster. J Ophthalmol 2012: 430249.
18. Jonas JB, Nangia V, Gupta R, Khare A, Sinha A, et al. (2012) Anterior chamber depth and its associations with ocular and general parameters in adults. Clin Exp Ophthalmol 40(6): 550-556.

19. Hosny M, Alio JL, Claramonte P, Attia WH, Perez-Santonja JJ (2000) Relationship between anterior chamber depth, refractive state, corneal diameter, and axial length. J Refract Surg 16(3): 336-340.

20. Jivrajka R, Shammas MC, Boenzi T, Swearingen M, Shammas HJ (2008) Variability of axial length, anterior chamber depth, and lens thickness in the cataractous eye. J Cataract Refract Surg 34(2): 289-294.

21. Yin G, Wang YX, Zheng ZY, Yang H, Xu L, et al. (2012) Ocular axial length and its associations in Chinese: the Beijing Eye Study. PLoS One 7(8): 43172.

22. Elabjer BK, Petrinović-Doresić J, Durić M, Busić M, Elabjer E (2007) Cross-sectional study of ocular optical components interactions in emmetropes. Coll Antropol 31(3): 743-749.

23. Yebra-Pimentel E, González-Méijome JM, García-Resúa C, GiráldezFernández MJ (2008) The relationships between ocular optical components and implications in the process of emmetropization. Arch Soc Esp Oftalmol 83(5): 307-316.

24. Jm G, Mj G (2008) The Relationship Between Ocular Optic Components and Implications in the Process of Emmetropization. Arch Soc Esp Oftalmol 83(5): 307-316.

25. Chen MJ, Liu YT, Tsai CC, Chen YC, Chou CK, et al. (2009) Relationship between central corneal thickness, refractive error, corneal curvature, anterior chamber depth and axial length. J Chinese Med Assoc 72(3): 133-137.

26. Connell B, Brian G BM (1997) A case-control study of biometry in healthy and cataractous Eritrean eyes. Ophthalmic Epidemiol 4: 151-155.

27. Olurin $O$ (1977) Anterior chamber depths of Nigerians. Ann Ophthalmol $9(3): 315-326$.

28. Foster PJ, Alsbirk PH, Baasanhu J, Munkhbayar D, Uranchimeg D, et al. (1997) Anterior chamber depth in Mongolians: variation with age, sex, and method of measurement. Am J Disabled Ophthalmol 124(1): 53-61.

29. Shufelt C, Fraser-Bell S, Ying-Lai M, Torres M, Varma R (2005) Refractive error, ocular biometry, and lens opalescence in an adult population: the Los Angeles Latino Eye Study. Invest Ophthalmol Vis Sci 46: 4450-4460.

30. Pereira GC, Allemann N (2007) Ocular biometry, refractive error and correlation with height, age, gender and years of formal education. Arq Bras Oftamol 70(3): 487-493. 